\title{
Personalidade, Relações Objetais e Esquizoidia na Obra de Ronald Fairbairn
}

\author{
Carlos Augusto Peixoto Junior \\ Pontifícia Universidade Católica do Rio de Janeiro, Rio de Janeiro, Brasil
}

\begin{abstract}
RESUMO
O presente artigo pretende, primeiramente, analisar alguns princípios e conceitos básicos da teoria psicanalítica da personalidade criada por Ronald Fairbairn, tais como os de ego central, ego libidinal, ego antilibidinal, objeto excitante e objeto rejeitante, dentre outros. A partir desta análise, avalia-se em seguida o modo pelo qual estes conceitos contribuíram para a elaboração de uma perspectiva estrutural dinâmica do psiquismo, assim como para uma concepção de psicopatologia baseada em um ponto de vista estritamente relacional-objetal. Por último, discutem-se algumas das principais características e traços fundamentais da esquizoidia elencadas pelo autor, tanto no que se refere ao seu aspecto teórico quanto clínico.
\end{abstract}

Palavras-chave: personalidade; esquizoidia; fairbairn; relações objetais.

\begin{abstract}
Personality, Object Relations and Schizoid Experience in the Work of Ronald Fairbairn

This article intends first to look at some basic principles and concepts of the psychoanalytic theory of personality created by Ronald Fairbairn, such as central ego, libidinal ego, antilibidinal ego, rejecting object and exciting object, among others. From this analysis on, it evaluates the way in which these concepts have contributed to the development of a structural dynamic perspective of the psyche, as well as to a conception of psychopathology based on a point of view strictly object-relational. Finally, it discusses some of the key features and fundamental traits of the schizoid experience listed by the author, both in their theoretical and clinical aspects.
\end{abstract}

Keywords: personality; schizoid experience; fairbairn; object relations.

Antes de entrarmos diretamente no tema central deste trabalho, gostaríamos de iniciá-lo tecendo uma breve consideração sobre a obra de Ronald Fairbairn e sua situação nos campos psicanalíticos moderno e contemporâneo. Dentre outras possibilidades, o lugar relativamente marginalizado que Fairbairn ocupa hoje na psicanálise, ao menos no que se refere a citações explícitas de seus textos, parece derivar do fato de que o leitor que empreende o estudo de sua obra se encontra confrontado com uma prosa de estilo denso e com uma forma altamente abstrata de teorização. Nela nos deparamos com um conjunto de termos teóricos muito pouco familiares (como por exemplo, estrutura dinâmica, estrutura endopsíquica, ego central, ego libidi- nal, ego antilibidinal, objeto excitante, objeto rejeitante, etc.), os quais não foram adotados por muitos dos analistas teóricos subsequentes. Ainda que sua terminologia seja pouco utilizada correntemente, acreditamos que suas ideias tiveram um impacto considerável em teóricos importantes da psicanálise moderna e contemporânea, tais como Klein, Guntrip, Kohut e Kernberg, dentre outros.

Numa série de férteis e densos ensaios escritos no começo dos anos quarenta, Fairbairn desenvolveu uma pesquisa teórica que fornece a expressão mais clara da mudança do modelo estrutural-pulsional para o modelo relacional, ainda que também encontremos nela uma rigorosa teoria da libido revisada. O semi-

* Endereço para correspondência: Carlos Augusto Peixoto Junior - cpeixotoj@@terra.com.br 
-isolamento físico e acadêmico de Fairbairn nas províncias de Edimburgo na Escócia, e uma prática de estudos em filosofia facilitaram a sua corajosa reconsideração de longo alcance do edifício conceitual dentro do qual opera a teoria psicanalítica.

Embora Fairbairn inaugure sua obra inserindo-se bem no cerne da metapsicologia freudiana, voltada para a teoria do desenvolvimento psicossexual, não é difícil notar que ele desafia com frequência algumas das suas suposições e princípios básicos. Vale lembrar ainda que seu enfoque imediato não estava diretamente voltado para a prática clínica da psicanálise. $\mathrm{Na}$ realidade, ele achava que a maioria dos analistas ficaria corretamente indignada com a sugestão de que eles minimizavam suas preocupações a propósito das relações com outras pessoas no seu trabalho com os pacientes. Em vez disto, sua preocupação era com o fracasso na ampliação da experiência clínica com os pacientes ao mais básico de seus princípios teóricos. $\mathrm{O}$ autor argumenta que as suposições fundamentais e os suportes conceituais da teoria da libido e da teoria do desenvolvimento psicossexual representam ênfases mal colocadas e equívocos básicos quanto à motivação e à experiência humana.

Ao que nos parece, pelo menos em parte, a escassez de referências diretas à suas ideias na literatura psicanalítica não é proporcional à significância de sua contribuição dentro da história das ideias psicanalíticas.

Dado este contexto, o presente artigo pretende analisar alguns princípios e conceitos básicos da teoria psicanalítica fairbairniana a respeito da personalidade e do ego, para, em seguida, discutir algumas das principais características da esquizoidia elencadas pelo autor, tanto no que se refere ao seu aspecto teórico quanto clínico.

\section{A TEORIA DA PERSONALIDADE: DINÂMICA PSÍQUICA, ESTRUTURA E PSICOPATOLOGIA}

No centro das amplas e variadas contribuições de Fairbairn estão a sua crítica e a reformulação da clássica teoria pulsional. A fonte da energia motivacional, tanto para a teoria freudiana como para a kleiniana, continuou sendo o impulso pulsional. Neste sentido, do seu ponto de vista, à psicologia do ego e seus objetos foi sobreposta uma psicologia das pulsões anterior. Fairbairn argumentou que as suposições básicas sobre as quais descansa a teoria pulsional seriam errôneas e enganosas; em um sentido mais amplo, ele viu o seu trabalho como significando uma "reinterpretação das visões de Freud com base numa série diferente de princípios científicos subjacentes" (Fairbairn, 1946/1994, p. 149).

Fairbairn localizou o seu desacordo com a teoria pulsional em dois princípios básicos: (1) a libido não busca o prazer, mas o objeto; e (2) a pulsão é inseparável da estrutura. Ele argumenta que o objeto não está apenas embutido na pulsão desde o começo, mas que a característica principal da energia libidinal é a sua qualidade de busca de objeto. O prazer não é o objetivo final da pulsão, mas um meio para o seu fim real - a relação com um outro. A suposição de que energia é separável de estrutura subjaz à distinção de Freud (1923/1992) entre diferentes agências psíquicas no seu modelo estrutural - um id sem estrutura, com energias sem direção, e um ego com processos e mecanismos para usar energia, mas sem nenhuma energia própria. Fairbairn argumenta que esta separação de energia e estrutura deriva de uma visão do mundo físico própria ao século XIX, na qual o universo é concebido como um "conglomerado de partículas inertes, imutáveis e indivisíveis ao qual era conferida moção por uma quantidade fixa de energia separada das partículas em si" (Fairbairn, 1944/1994, p. 127).

Do ponto de vista fairbairniano, o que a metapsicologia clássica fez foi tomar a pessoa humana, que é energia operando em modos direcionais (para objetos), para sobrepor a esse processo natural uma distinção artificial entre as atividades e a energia que supostamente as move. Para o autor, a visão do ego como um aparelho, com estruturas sem energia, é uma distorção linguística da atividade humana original, energizada e estruturada. Assim, não há nenhuma separação de ego e id. Não há nenhum poço de energia sem direção que se torna secundariamente orientada para objetos. As estruturas do ego têm energia - elas são energia - e esta se mostra estruturada e direcionada para os objetos desde o seu início. As pulsões, portanto, não podem ser separadas destas estruturas e das relações objetais que elas permitem que o ego estabeleça.

Segundo Greenberg e Mitchell,

[...] o que Fairbairn está sugerindo é, na realidade, uma visão fundamentalmente diferente da motivação, significados e valores humanos. De acordo com o modelo estrutural-pulsional clássico, o bebê hu- 
mano nasce fundamentalmente não relacionado a outros, buscando a redução de tensão; torna-se relacionado a outros apenas secundariamente, devido à sua utilidade em reduzir as suas tensões, fornecerlhe prazer. Fairbairn sugere que o bebê é orientado para outros desde o começo e que sua busca de relação tem raízes adaptativas na sua sobrevivência biológica (Greenberg \& Mitchell, 1994, p. 114).

Fairbairn sustenta que a criança está tão orientada para a realidade, a mãe, como estão os animais inferiores, mas que, sem os comportamentos préprogramados, instintivos, "o seu caminho para a mãe está mais duramente traçado" (Fairbairn, 1946/1994, p. 140). O aparente caos e o comportamento a esmo dos primeiros meses não refletem um estágio narcísico primário ou autoerótico no qual o bebê não está dirigido a objetos para satisfazer suas necessidades. $\mathrm{O}$ aparente estado ao acaso simplesmente reflete inexperiência. Sem configurações embutidas, ele ponderava, leva tempo para o bebê humano aprender como fazer contato e organizar as suas relações com a sua mãe (Fairbairn, 1946/1994).

Já no que se refere à estruturação psíquica Fairbairn imagina um ego unitário, completo com sua própria energia libidinal, que busca relações com objetos externos reais. Se estas relações são satisfatórias, o ego permanece completo e inteiro. Relações insatisfatórias com objetos externos naturais necessitam do estabelecimento de objetos internos compensatórios. A cisão do ego é uma consequência da proliferação destes objetos internos, uma vez que porções diferentes dele permanecem relacionadas a diferentes objetos internos. Esta ligação e devoção por parte do ego a seus objetos internos causa uma fragmentação do ego original integral.

$\mathrm{Na}$ visão do autor, o relacionamento com a mãe tem dois traços fundamentais: um componente gratificante e um componente não gratificante. $\mathrm{O}$ aspecto não gratificante consiste não só em rejeição, mas em uma rejeição seguida de algum sentimento de esperança ou promessa. Nestas condições, a criança teria três experiências diferentes da mãe: uma gratificante, outra sedutora e uma terceira, privadora. O psicanalista britânico denomina os três objetos internos que advém destas experiências de objeto ideal (aspectos gratificantes da mãe), objeto excitante (aspectos promissores e sedutores da mãe) e objeto rejeitante (aspectos privadores, sonegadores da mãe).

Conforme vimos, um princípio básico no sistema estrutural fairbairniano é o de que ego e objeto são inseparáveis. Para ser importante, um objeto deve ter uma parte do ego ligada a ele.

Um ego sem objeto é uma contradição de termos

[...] o objeto excitante e o objeto rejeitante são "maus" objetos, no sentido que Fairbairn dá ao termo, porque não são gratificantes. O ego mantém relações com estes maus objetos internos num esforço para controlá-los e preservar as suas relações com a mãe real sem contaminá-las por frustração, raiva e anseios não gratificados. (Greenberg \& Mitchell, 1994, p. 121)

No entanto, a criança também internaliza um bom objeto, o objeto ideal, composto daqueles traços da mãe que permanecem depois que as porções sobreexcitantes e sobre-rejeitantes são separadas.

O ego libidinal é aquela parte do ego original da criança que não desistiu dos anseios e exigências insatisfeitas da dependência infantil. Ele é o repositório da esperança e, na sua ligação ao objeto excitante, permanece preso a imagens de promessas não cumpridas, seduções e potenciais para contato com a mãe que nunca foram desfrutados. O ego libidinal anseia por união com o objeto excitante, como uma relação objetal interna, porque o anseio por gratificação real da mãe real tornou-se demasiado doloroso. O ego libidinal, portanto, permanece num relacionamento perpétuo e carente com o objeto excitante (Fairbairn, 1944/1994). A promessa é mantida viva, mas a realização é impossível.

De acordo com Thomas Ogden, se considerarmos o vínculo entre o ego e os objetos internos de Fairbairn do ponto de vista da vida emocional

[...] a relação entre o ego libidinal e o objeto excitante é a de um 'amor' viciado por parte do ego libidinal, acompanhada da necessidade desesperada do objeto excitante no sentido de evocar o desejo por parte do ego libidinal (cujo desejo o objeto excitante nunca satisfará) (Ogden, 2010, p. 108)

O ego antilibidinal é a parte do ego que se torna o repositório para todo o ódio e destrutividade que se acumulam em consequência da frustração do anseio libidinal. Ele está ligado a e identificado com o objeto rejeitante, o aspecto da mãe sentido como privador e sonegador. Representa, portanto, a parte do ego que, como não foi gratificada pelas seduções maternas, identifica-se com aqueles seus traços que privam e sonegam (Fairbairn, 1946/1994). Estes ataques internos pelo ego antilibidinal são responsáveis por aspec- 
tos autodestrutivos e autopunitivos da psicopatologia, tal como veremos mais adiante. $\mathrm{O}$ ego antilibidinal é o inimigo da esperança, principalmente da esperança por qualquer coisa significativa com outras pessoas. Ele odeia e pune o ego libidinal por quaisquer tentativas para conseguir algo dos outros e odeia aquela outra pessoa que oferece uma possibilidade de relacionamento. Assim,

[...] na situação psicanalítica, por exemplo, um período de maior contato entre um paciente gravemente perturbado e o analista é quase sempre seguido por poderoso ódio por parte do paciente, de si e do analista. Nos termos de Fairbairn, isto é o ego antilibidinal punindo o ego libidinal e o objeto excitante tanto o sujeito como o objeto de relacionamento possível. (Greenberg \& Mitchell, 1994, p. 122)

A relação entre o ego antilibidinal e o objeto rejeitante deriva do amor infantil pela mãe a despeito (mas também por causa) de sua rejeição para com ele. A natureza do amor patológico que liga o ego antilibidinal e o objeto rejeitante não constitui propriamente um laço de ódio, mas um amor patológico que é experimentado como um amargo "ressentimento" (Fairbairn, 1944/1994, p. 115). Nem o objeto rejeitante nem o ego antilibidinal querem ou estão aptos a pensar sobre, e menos ainda a abandonar, este laço. De fato, não há nenhum desejo da parte de ambos para mudar alguma coisa a propósito de sua dependência mútua.

Os maus-tratos nas mãos do outro são sentidos como imperdoáveis. Uma desculpa é sempre esperada por cada um deles, mas nunca oferecida por nenhum dos dois. Nada é mais importante para o ego antilibidinal (o self rejeitado) do que coagir o objeto rejeitante a reconhecer a dor incalculável que ele ou ela causa (Ogden, 2010, p. 109)

Já o ego central é uma estrutura endopsíquica capaz de pensamento, sentimento, respostas, etc. Ele constitui o self original saudável do bebê recém-nascido. Desde o começo, o ego central é capaz de diferenciar de forma rudimentar self e objeto, e de operar na base do princípio de realidade. Mas em resposta a uma experiência traumatizante com uma mãe que ao mesmo tempo em que ama e aceita o seu amor, não o ama e o rejeita, o bebê cliva partes do ego central e as reprime na forma de relações de objeto internas. Consequentemente, o ego central retém sua saúde original, mas é significativamente esvaziado pelo processo de clivagem, que implica em uma espécie de "envio para o exílio" (repressão) de partes de si mesmo (Fairbairn, 1943/1994).

Nestes termos, o ego central é a única parte do self que está apta a se engajar na e aprender com a experiencia junto aos objetos externos. A mudança no mundo inconsciente dos objetos internos é sempre mediada pelo ego central. Para Ogden, "ele não inclui qualquer relação de objeto interno dinamicamente reprimida (insatisfatória); na verdade, o ego central consiste exclusivamente em relações de objeto suficientemente boas (opostas às idealizadas), tais como as identificações com pessoas que foram amadas e por quem se foi amado, reconhecido e aceito" (Ogden, 2010, p. 103). Tais identificações formam a base de sentimentos que incluem um senso de segurança interna, assim como sentimentos básicos de solidariedade e integridade.

No que diz respeito à psicopatologia, Fairbairn a vê fundamentalmente como uma tentativa do ego de perpetuar laços e esperanças antigos representados por objetos internos. A psicopatologia portanto é compreendida, antes de tudo, não como derivando de conflitos entre impulsos que buscam prazer, mas como um quadro que reflete distúrbios e interferências provenientes das relações com os outros. O aspecto crucial da maturidade saudável, nestes termos, diria respeito à capacidade para uma rica e íntima mutualidade compartilhada com o outro.

Se o bebê está orientado para a realidade (para os objetos) desde o início, a pura busca de prazer seria o reflexo de uma deterioração do funcionamento libidinal natural (relacionado ao objeto). $\mathrm{O}$ uso do prazer por descarga de tensão serve como uma válvula de escape; funciona não como um meio de atingir objetivos verdadeiramente libidinais, mas como um "meio de mitigar o fracasso destes objetivos" (Fairbairn, 1949/1994, p. 139-40). A consequência do que Fairbairn considera uma relação não natural é que as primeiras relações com objetos tornam-se "más" ou privam. É doloroso demais ansiar por e depender de um objeto que está física ou emocionalmente ausente grande parte do tempo. Assim, a criança estabelece objetos internos dentro de si que agem como substitutos e "soluções" para relacionamentos não satisfatórios com objetos externos reais. Quanto maior o grau de interferência e privação nas relações com seus objetos "naturais", pessoas reais, maior a necessidade do ego em estabelecer relações com objetos internos. Estes seriam então, por definição, estruturas patológicas. 
Do ponto de vista fairbairniano a internalização inicial de objetos deriva da intensa necessidade da criança por um relacionamento consequente, a qual é imposta por pais emocionalmente ausentes, intrusos ou caóticos. Diante da necessidade de preservar a ilusão da bondade dos pais como figuras reais no mundo externo, a criança separa e internaliza os seus maus aspectos - não são eles que são maus, mas ela. A maldade está dentro dela; se ela fosse diferente o amor deles seria possível. Toda criança precisa compreender que seus pais são justos e confiáveis e, se ela não os sente assim, transfere o problema para si, ou seja, toma para si a "carga de maldade". A "maldade", as qualidades não desejáveis dos pais - isto é, a depressão, a desorganização, o sadismo - agora estão nela. Estes "maus" traços tornam-se maus objetos com os quais o ego se identifica (através da identificação primária). A criança adquiriu a segurança externa ao preço de sacrificar a segurança interna acrescida de mais esperança ilusória.

Em 1943, o autor distinguiu diferenças qualitativas entre os tipos de patologia baseadas na: (1) extensão de maus objetos e grau de maldade deles; e (2) extensão da identificação do ego com estes objetos e a natureza e a força das defesas que protegem o ego dos objetos (Fairbairn, 1943/1994). Mais tarde, ele acrescentará à sua teoria da repressão de maus objetos a perspectiva de que porções do ego acompanham estes objetos no decorrer da repressão, resultando numa cisão do ego. $\mathrm{O}$ grau de patologia, neste contexto, depende de quanto do ego ainda permanece disponível para relações reais e potencialmente gratificantes com outros e do quanto fica ligado a aspectos não gratificantes e inalcançáveis dos pais, os quais se tornam entesourados internamente. A culpa, neste processo, surge secundariamente, através da "defesa moral". A criança se sente má do ponto de vista moral a fim de abrir a possibilidade de tornarse moralmente boa, e, deste modo, reconquistar boas relações com o objeto (Fairbairn, 1944/1994). Como vimos, Fairbairn acredita que ela tenta proteger o que é gratificante e controlar o que não é, estabelecendo relações objetais internas compensatórias. É na "ligação obstinada" (Fairbairn, 1944/1994, p. 117) do ego libidinal com o objeto excitante que a criança conserva suas esperanças de um maior e mais satisfatório contato com os pais.

A experiência destas relações objetais internas e a projeção delas no mundo externo produzem o sofrimento humano patológico. Os objetos de amor são selecionados como ou transformados em sonegadores ou privadores a fim de personificar o objeto excitante, promissor, mas nunca satisfatório. A derrota é orquestrada repetidamente para perpetuar o anseio e a necessidade de satisfação do ego libidinal diante da promessa do objeto excitante.

Depressão, terror e futilidade representam as identificações do ego com "maus" aspectos dos pais que não podiam ser alcançados através de um intercambio real com eles no mundo externo e, assim, foram levados para dentro.

A psicopatologia persiste, dores antigas retornam, configurações destrutivas na integração de relações com os outros e sentir a vida são perpetuadas - porque, sob a dor e as relações e organizações de experiências autoderrotistas, jazem ligações internas e lealdades antigas para com os outros significativos anteriores. A recriação da dor, do sofrimento e da derrota é uma forma de renovação e devoção a estes laços. A relutância em trair estas ligações através de novas relações e lealdades impede a mudança construtiva no viver e resulta numa resistência central e intransigente (Greenberg \& Mitchell, 1994, pp. 127-28).

\section{AS TESES SOBRE A EXPERIÊNCIA ESQUIZOIDE: TEORIA E CLÍNICA}

Talvez as ideias mais inovadoras de Fairbairn sejam aquelas que concernem não apenas a estrutura endopsíquica, comentadas brevemente acima, como também à condição esquizoide que a subentende. Tal condição constitui, pelo menos em parte, o destino do homem, na medida em que a cisão é inerente a ele como uma consequência inevitável da experiência humana. Para Grotstein e Rinsley “o próprio estabelecimento da estrutura endopsíquica é então um testemunho arquivístico de momentos arcaicos dos desapontamentos críticos. Nestes termos, nenhum indivíduo poderia deixar de ser minimamente patológico" (Grotstein \& Rinsley, 1994, p. 11). O bebê esquizoide fairbairniano acredita que o seu amor é mau porque não foi validado. Como vimos, atribuindo a rejeição da mãe à sua maldade à priori, ele acaba por acreditar que o seu amor é inerentemente destrutivo (cruelmente predatório). Fairbairn considerava que a presença (ou ausência) do amor materno no estágio oral precoce (pré-ambivalente) colocaria o bebê em risco, dado que ele acreditaria que o amor é mau e perigoso, o que instigaria, portanto, o retraimento esquizoide, neste 
caso, defensivo. Assim, nosso autor atribui a patologia não propriamente a destrutividade ou ao ódio, mas ao fracasso na capacidade de amar e ser considerado como uma pessoa por direito próprio.

Ao mesmo tempo, o autor sustenta que qualquer bebê percebe realisticamente os limites na capacidade de sua mãe para amá-lo, e que essa percepção realista é "traumática" para ele (Fairbairn, 1944/1994, p. 110). A lógica é a seguinte: (1) "Todos sem exceção devem ser vistos como esquizoides" (Fairbairn, 1940/1994, p.7), ou seja, todo mundo evidencia uma cisão patológica do self - as pessoas se diferenciam umas das outras apenas na severidade da sua patologia esquizoide; (2) a psicopatologia esquizoide tem sua origem em uma relação "insatisfatória" com a mãe, isto é, há uma "falha da parte da mãe em convencer a criança de que ela realmente a ama como pessoa" (Fairbairn, 1940/1994, p. 13); (3) na medida em que todo mundo é esquizoide, e que a condição esquizoide deriva da falha materna em convencer o bebê do seu amor, segue-se que todo bebê experimenta um fracasso traumatizante com o amor materno. Na visão de Fairbairn, todas as crianças interpretam mal privações inevitáveis como falta de amor da mãe por elas. Deste ponto de vista, a concepção fairbairniana a respeito do desenvolvimento psíquico precoce

[...] é uma teoria do trauma na qual a criança, em graus variados, é traumatizada pela sua percepção realística de que é totalmente dependente de uma mãe cuja capacidade de amá-la passou do seu ponto de ruptura. Fairbairn acredita na primazia da realidade externa e no papel secundário da fantasia, contrariamente a Melanie Klein. (Ogden, 2010, p. 103)

Nota-se então que o autor modificou o significado e a relativa importância do conceito "esquizoide" retirando-o de uma classe especifica e estreita de desordens existenciais para situá-la em um tipo de categoria mais ampla que comporta qualquer subjetividade atingida por divisões em sua estrutura de ego. Com isso, ele efetivamente promoveu uma transformação nos termos do "diagnóstico" psicanalítico a propósito da esquizoidia, que excluía apenas indivíduos com uma saúde mental notavelmente boa. Assim, vários tipos não neuróticos foram incluídos em sua definição. Mas Fairbairn não estava apenas expandindo a definição de esquizoidia para incluir uma ampla variedade de conflitos; ele também estava mudando o seu estatuto de uma modalidade de sofrimento específico para uma forma de subjetivação definida pelo processo psíquico de divisão do ego, considerado como a base de vários quadros clínicos (Fairbairn, 1941/1944).

Segundo Paul Celani, Fairbairn também percebeu que

[...] o indivíduo esquizoide tem três características que hoje são bem conhecidas: a onipotência, um senso de desligamento e um foco excessivo no mundo interno. Todas as três características são consequência de várias formas de privação maturacional isto é, de uma relação fracassada com os objetos mais primários. (Celani, 2010, p. 27)

A fonte da tendência esquizoide seria então efeito de uma relação interpessoal fracassada, da falta de sintonia, da indiferença e da ausência de vínculo emocional por parte da mãe, vividas nas mais diversas modalidades de sofrimento emocional.

Conforme dizíamos antes, na perspectiva fairbairniana a estabilidade dos laços inconscientes com os objetos internos é a principal fonte de estabilidade na organização da personalidade de qualquer indivíduo. $\mathrm{O}$ apego inconsciente aos objetos internos constitui a "substância aderente" que mantém juntas todas as organizações da personalidade. Nas esquizoidias mais graves, essa "substância" produz um apego tão intenso aos objetos internos que o envolvimento emocional com os objetos da realidade é quase completamente excluído. Nestes casos extremos, a energia psíquica é retirada não apenas das relações com os objetos externos, mas também dos objetos internos. O resultado é o que Fairbairn chama de "perda do ego" (Fairbairn, 1941/1994). Ainda assim, o autor nos diz que é possível reconhecer como essencialmente esquizoides não apenas fenômenos confirmados de despersonalização e desrealização, mas também problemas relativamente menores na percepção da realidade, tais como sentimentos "de artificialidade" (quer se trate do self ou do ambiente), o sentimento de estranheza diante de pessoas ou lugares conhecidos e o sentimento de familiaridade com o desconhecido (Fairbairn, 1940/1994, p. 5).

Segundo Thomas Ogden (1989), quando um objeto externo fracassa em se conformar com o roteiro e a direção ansiados pelo indivíduo, o uso de elementos como negação, desprezo, grandiosidade, distorção de percepção e retraimento emocional servem para reduzir ao mínimo o impacto da experiência com o objeto externo. Em consequência disso o indivíduo não se deixa transformar por sua experiência no mundo. Inconscientemente ele sabe que é um ator aprisionado 
no seu próprio drama interno e, nestas condições, experimenta profundos sentimentos de futilidade $\mathrm{e}$ vazio.

Mas o vazio do paciente esquizoide não é apenas aquele da solidão; ele é também o vazio da ausência de apoio em qualquer coisa que exista fora de sua própria mente. "Trata-se, no caso, do vazio de um self amplamente desconectado da experiência intersubjetiva humana, através da qual o self comumente adquire um sentido sobre sua própria realidade através do reconhecimento do outro" (XXXX, 2011, p. 95). Em geral, o paciente esquizoide só está ocupado e preocupado com suas relações objetais internas; além disso, essas relações, em si mesmas, são muito pouco substanciais e levam a um estado de empobrecimento emocional.

Tendo em conta o desligamento deste tipo de paciente na transferência, Fairbairn também buscou as causas deste processo ativo de desvinculação e divisão do ego, assim como os conflitos que antecediam o complexo de Édipo e a consolidação do superego. Ele notou com frequência que as personalidades esquizoides, na tentativa de se retrair dentro da transferência, estavam se defendendo da temível ativação de uma relação terapêutica básica, caracterizada por um investimento libidinal do analista experimentado como uma mãe pré-edipiana, particularmente oral. Esta modalidade de investimento libidinal se assemelhava a uma grande ameaça para estes pacientes, derivada do medo de que seu amor pelo objeto pudesse ser devastadoramente destrutivo para este último.

De acordo com Otto Kernberg, analisando este medo,

Fairbairn encontrou uma constelação típica de sentimentos e fantasias, refletindo essencialmente a convicção do paciente de que o seu próprio amor pela mãe teria qualidades que exaurem e esvaziam a mãe, sendo, portanto, destrutivas para ela e que, ao mesmo tempo, ameaçam o paciente com um sentimento fundamental de futilidade, uma sensação de depleção relacionada ao gasto do seu próprio amor na ausência de um objeto receptivo e responsivo [...] A frustração do paciente derivada de sua percepção da falta de amor da mãe faz com que ele experimente o seu próprio amor como demandante e agressivo. (Kernberg, 1994, p. 46)

Fairbairn concluiu que, por causa de um medo profundo de que suas necessidades de amar e serem amados fossem frustradas, os indivíduos esquizoides luta- vam inconscientemente contra um verdadeiro investimento nos outros e regrediam para e/ou se fixavam em um estágio de relações objetais essencialmente receptivo, demandante, no qual experimentam a si próprios como alguém que está apenas do lado de quem pede, evitando cuidadosamente ter que dar de si mesmo. Dar, em tal caso, torna-se equivalente a ser esvaziado, um resto catastrófico do sentido de depleção derivado do investimento libidinal não atendido. Os esforços para evitar "dar" podem reforçar a necessidade de reprimir quaisquer afetos para evitar um investimento afetivo. Fairbairn via o sentimento de desperdício, de irrealidade de intensa autoconsciência e constante auto-observação dos pacientes esquizoides como consequências do empobrecimento do seu ego central pela divisão excessiva. $\mathrm{O}$ estudo do desenvolvimento da transferência nestes pacientes ofereceu a ele a evidência de que haveria uma "des-emocionalização" das relações objetais, resultando no desapego característico dos pacientes das relações com objetos externos, lado a lado com uma intensa preocupação com a realidade interna.

No entanto, a perda ou a atenuação dos contatos externos contam uma boa parte da história da esquizoidia, mas não toda a história: contam a parte do pânico. Essa perda de contatos realmente diz respeito a uma dimensão do sofrimento muito séria e radical: a do amortecimento e silenciamento das forças pulsionais, que se voltam quase exclusivamente para o "mundo interno", gerando uma profunda sensação de tédio e futilidade, tal como indicamos anteriormente, a qual poderia ser confundida erroneamente com a depressão. Mas este tédio e esta futilidade são mais radicais: eles dão o tom dominante dos estados esquizoides nos seus momentos mais sombrios, em que absolutamente nada pode ser dotado, no presente, no passado ou no futuro, de qualquer valor afetivo, de qualquer apelo positivo ou negativo.

Esses estados esquizoides emergem ao final de um percurso fracassado de busca de contato e da consequente construção de estruturas endopsíquicas que se cronificam em um sistema fechado. Como nos mostra Luiz Claudio Figueiredo,

[...] na derradeira estação da viagem esquizoide, uma estabilidade psíquica é finalmente alcançada, mas cobrando o alto preço de uma retirada do mundo, uma profunda desvinculação e um opressivo sentimento de futilidade. Na esquizoidia, produto derradeiro do movimento básico de construção do psi- 
quismo, realiza-se integralmente o processo esquizoide que, ao mesmo tempo em que constituía nosso psiquismo como defesa contra o trauma, nos remetia ao gélido isolamento dos astros infinitamente distantes uns dos outros. (Figueiredo, 2003, p. 54)

A outra parte da história não é a do tédio, mas a do pavor, e este pode ser muitas vezes a única fonte de calor neste mundo gelado da esquizoidia.

A crescente dissociação entre partes da experiência do indivíduo dá, a cada uma, um dinamismo próprio e uma independência que emprestam a esse lugar de interioridade, em que supostamente se encontra refúgio, o colorido da turbulência e da desintegração. Os objetos internos podem adquirir um dinamismo independente que não pode ser ignorado, ou seja, eles se transformam efetivamente em fontes de energia, em dínamos da vida psíquica.

Ao contrário do que parecia ser a marcha natural do processo na direção do desligamento silencioso e do fechamento dos sistemas, quando os objetos internalizados são mais que objetos para se converterem em estruturas dinâmicas, o psiquismo passa a ser agitado "de dentro" por elementos que contrariam todo o sossego que o sistema fechado esquizoide promete e aparentemente proporciona. Ao internalizar seus maus objetos para melhor controlá-los, o indivíduo não imaginava que ficaria, mais que antes, à mercê deles em suas duplas e inconciliáveis facetas. Trata-se de abrigar em si mesmo corpos estranhos intratáveis e desarmônicos.

Discutindo a situação de um ponto de vista clínico, Figueiredo afirma que

[...] no caso do paciente esquizoide os limites da interpretação podem ser bastante grandes, pois não faz sentido a tarefa de interpretar comportamentos dissociados de fantasias e afetos congelados. No entanto, as interpretações podem ocorrer com a função de holding verbal, a serviço do manejo da regressão e da instalação da confiança como passos preliminares para o descongelamento afetivo, para a superação das cisões e dissociações, para o contato com o mundo dos afetos e das fantasias na regressão e para a instalação subsequente da capacidade do sonho e do espaço do jogo. (Figueiredo, 2003, pp. 148-49)

Quando se constitui o sistema fechado (Fairbairn, 1958), o paciente esquizoide profundo torna-se impermeável às experiências com novos objetos, ficando encarcerado na estrutura e na dinâmica mantidas por seus demoníacos maus objetos internos. O medo e o pavor dominam a situação, e quando surge algo parecido com a esperança, trata-se apenas, na verdade, da ingenuidade diante de maus objetos que assumem a forma da tentação e da sedução. Sem o rompimento desse sistema em que o sujeito fica aprisionado entre seus objetos maus, persecutórios e sedutores, o trabalho terapêutico não pode caminhar.

\section{CONSIDERAÇÕES FINAIS}

A título de conclusão, diríamos que a maioria dos autores que lançaram mão da obra de Fairbairn, o fez acima de tudo para enfrentar os desafios teóricos e clínicos dos chamados "pacientes difíceis", borderlines, narcísicos assim como dos casos ainda mais graves de franca esquizoidia. Uma resposta fairbairniana a esse uso restritivo, como vimos no decorrer deste artigo, seria dizer que toda e qualquer subjetivação comporta certa esquizoidia, seja como fase inicial e estrutura básica da construção do psiquismo, seja como quadro sintomático em certas situações-limite pelas quais todos passamos, seja, ainda, como estrutura de caráter singular após uma sucessão de desastres existenciais profundos. A própria instituição de um "interior" relativamente isolado, um psiquismo investido e estruturado, já seria da ordem da psicopatologia esquizoide.

Os diversos quadros neuróticos, psicóticos e perversos seriam estratégias sintomáticas habituais e estruturadas para lidar com uma esquizoidia sempre subjacente. Essas estratégias, quando falham ou faltam, dariam lugar aos quadros esquizoides propriamente ditos em que a dominância de inúmeras cisões egóicas e objetais impediriam um nível mais consistente de integração subjetiva, mas, ao mesmo tempo e paradoxalmente, gerariam uma "estabilidade" e uma resistência à mudança surpreendente (Figueiredo, 2003, p. 46).

Para Fairbairn, uma mudança psicológica como essa, que poderia ser alcançada através da psicanálise, apesar dos mais diversos obstáculos terapêuticos próprios a estes casos, envolveria primariamente diminuições de intensidade dos sentimentos de ressentimento, amor viciado, desprezo, dependência primitiva, desilusão, etc., que conjugariam as suborganizações cindidas e reprimidas do self umas com as outras.

Embora Fairbairn nunca coloque desse modo, parece-nos que o princípio psicológico mais fundamental que sustenta a sua concepção de amadurecimento 
emocional é a ideia de que toda maturação comportaria a aceitação genuína de si mesmo por parte do próprio indivíduo e, por extensão, também dos outros. Esta aceitação poderia ser alcançada através do difícil e extenuante trabalho, muitas vezes infrutífero, pelo qual se chegaria a uma espécie de acordo com uma ampla variação de aspectos do self, incluindo aí identificações perturbadas, infantis ou cindidas com uma mãe que não ama e não aceita, tal como ocorre com os esquizoides. Uma mudança emocional deste tipo, ainda que comporte um tom excessivamente otimista, talvez criasse a possibilidade de descobrir um mundo de pessoas e experiências que existiria fora do próprio mundo estritamente subjetivo, no qual seria possível se sentir curioso, surpreso, satisfeito, desapontado, saudoso, etc. "Este também é um mundo no qual se pode aprender com a experiência mantida com os outros porque estas experiências não são mais dominadas por projeções de relações de objeto interno estáticas" (Ogden, 2010, p. 114).

$\mathrm{O}$ amadurecimento emocional, para Fairbairn, envolve, portanto, uma forma de aceitação de si mesmo que só poderia ser alcançada no contexto de uma relação real com uma pessoa relativamente madura em termos psíquicos. Um relacionamento deste tipo (incluindo a relação analítica) seria uma saída possível do mundo solipsista de relações de objeto internas que caracteriza a esquizoidia. No caso da análise, como ele mesmo dizia, "o fator realmente decisivo (terapêutico) é o relacionamento do paciente com o analista" (Fairbairn, 1958, p. 379). No entanto, Fairbairn também nunca deixou de nos alertar para o fato de que tal relacionamento nem sempre é suficientemente exitoso no que se refere aos objetivos terapêuticos almejados com os pacientes esquizoides no decurso de uma análise.

A autoaceitação é um estado mental que marca o abandono (nunca completamente realizado) do esforço para transformar relações de objeto internas insatisfatórias em satisfatórias (ou seja, amáveis e aceitáveis), esforço que pode consumir toda uma vida e ainda assim não ser bem sucedido. Com o crescimento psicológico, o sujeito chegaria a compreender em profundidade que suas experiências precoces com uma mãe que não o amava e não o aceitava nunca serão nada além do que foram. Seria uma perda de tempo devotar-se ao esforço de se transformar (e transformar os outros) na pessoa que queriam que fôssemos (ou queríamos que fossem). Para que pudesse tomar parte na experiência de um mundo povoado por pessoas que não inventou, e com as quais poderia aprender, todo indivíduo, e antes de tudo o esquizoide, precisaria primeiramente afrouxar os laços inconscientes de ressentimento, amor viciado, desprezo e desilusão que muitas vezes o confinam a uma existência vivida principalmente dentro de sua própria mente. Quem sabe assim seria possível descobrir que a vida e os encontros que ela oferece valem a pena.

Este talvez tenha sido o mais importante legado de Fairbairn com seu estudo da personalidade como um todo e, mais especificamente, com a abordagem da experiência esquizoide. Um legado paradoxal que, com todo o seu aparente otimismo no que se refere às possibilidades de investigação teórico-clínica da esquizoidia, nunca esqueceu as enormes dificuldades técnicas inerentes a esta experiência. Ao contrário, Fairbairn certamente foi, na história da psicanálise, um dos que mais se dedicou ao enfrentamento destas questões tão difíceis, não apenas para o seu tempo como também para a clínica psicanalítica atual.

\section{REFERÊNCIAS}

Celani, D. P. (2010). Fairbairn's object relations theory in the clinical setting. New York: Columbia University Press.

Fairbairn, W. R. D. (1994). Schizoid factors in the personality. In Psychoanalytic studies of the personality (pp. 3-28). London: Routledge. (Trabalho original publicado em 1940)

Fairbairn, W. R. D. (1994). A revised psychopathology of the psychoses and psychoneuroses. In Psychoanalytic studies of the personality (pp. 29-60). London: Routledge. (Trabalho original publicado em 1941)

Fairbairn, W. R. D. (1994). The repression and the return of bad objects (with special reference to the war neurosis). In Psychoanalytic studies of the personality (pp. 61-86). London: Routledge. (Trabalho original publicado em 1943)

Fairbairn, W. R. D. (1994). Endopsychic structure considered in terms of object-relationships. In Psychoanalytic studies of the personality (pp.87-146). London: Routledge. (Trabalho original publicado em 1944).

Fairbairn, W. R. D. (1994). Object-relationships and dynamic structure. In Psychoanalytic studies of the personality (pp. 147162). London: Routledge. (Trabalho original publicado em 1946)

Fairbairn, W. R. D. (1994). Steps in the development of an objectrelations theory of the personality. In Psychoanalytic studies of the personality (pp. 163-172). London: Routledge. (Trabalho original publicado em 1949)

Fairbairn, W. R. D. (1958). On the nature and aims of psychoanalysis. International Journal of Psychoanalysis, 39, 374-385. 
Figueiredo, L. C. (2003). Psicanálise: elementos para a clínica contemporânea. São Paulo: Editora Escuta.

Freud, S. (1992) El yo y el ello (J. L. Etcheverry, Trad.). In Obras completas (vol. 19, pp. 3-66). B. Aires: Amorrortu editores. (Trabalho original publicado em 1923).

Greenberg, J. R. e Mitchell, S. A. (1994). Relações objetais na teoria psicanalítica (E. O. Diel, Trad.). Porto Alegre: Artes Médicas.

Grotstein, S. e Rinsley, D. B. (1994). Introduction. In Grotstein, S. e Rinsley, D. B. (orgs.) Fairbairn and the origins of object relations (pp. 3-16). London: Free Association Books.

Kernberg, O. (1994). Fairbairn's theory and challenge. In Grotstein, S. e Rinsley, D. B. (orgs.), Fairbairn and the origins of object relations (pp. 41-65). London: Free Association Books.
Ogden, T. H. (1989). The primitive edge of experience. NY: Basic books.

Ogden, T. H. (2010). Why read Fairbairn? International Journal of Psychoanalysis, 91, 101-118.

Peixoto Junior, C. A. (2011). Os limites da representação na experiência esquizoide. In Garcia C. A. e Cardoso, M. R. Limites da clínica, clínica dos limites (pp. 93-103). Rio de Janeiro: Cia. de Freud/Faperj.
Recebido em 31/08/2012 Última Revisão em 20/05/2013 Aceito em 30/05/2013 